\title{
Arene-Bridged Dithorium Complexes: Inverse Sandwiches Supported by a $\delta$ Bonding Interaction
}

\author{
Chao Yu, Jiefeng Liang, Chong Deng, Guillaume Lefêvre, Thibault Cantat, Paula L. Diaconescu,* \\ and Wenliang Huang*
}

Cite This: https://dx.doi.org/10.1021/jacs.0c11215

Read Online

ABSTRACT: A series of arene-bridged dithorium complexes was synthesized via the reduction by potassium graphite of a Th(IV) precursor in the presence of arenes. All these compounds adopt an inverse-sandwich structure, with the arene bridging two thorium centers in a $\mu-\eta^{6}, \eta^{6}$-mode. Structural and spectroscopic data support the assignment of two Th(IV) ions and an arene tetraanion, which is an aromatic structure according to Hückel's rule. Arene exchange reactions revealed that the stability of the corresponding compounds follows the series naphthalene $\ll$ toluene $<$ benzene $\approx$ biphenyl. Reactivity studies showed that they function as fourelectron reductants capable to reduce anthracene, cyclooctatetraene, alkynes, and azobenzene, while a mononuclear thorium anthracene complex could reduce benzene. Density functional theory calculations unveiled that the bonding interactions consist of $\delta$ bonds between thorium $6 \mathrm{~d}$ and $5 \mathrm{f}$ orbitals and arene $\pi^{*}$ orbitals, showing a significant covalent character, able to stabilize highly reduced arene ligands.

f-Element arene interactions ${ }^{1-3}$ proved critical in f-element catalysis $^{4-7}$ and stabilizing novel oxidation states. ${ }^{8-12}$ Among f-element arene complexes, arene-bridged dinuclear compounds with an inverse-sandwich structure are arguably the most studied. ${ }^{2,3}$ Examples include benzene-bridged dinuclear lanthanide complexes, ${ }^{13-17}$ tetraanionic biphenyl-bridged dinuclear rare-earth metal complexes, ${ }^{18,19}$ and, most notably, a large number of arene-bridged diuranium complexes. ${ }^{3,20-33}$ The remarkable robustness of the inverse-sandwich diuranium arene motif was emphasized by a ready exchange of the ancillary ligand, ${ }^{23}$ a facile change of metal oxidation states, ${ }^{28,30}$ and $\mathrm{C}-\mathrm{H}$ borylation of the arene. ${ }^{27}$ In-depth experimental and computational studies elucidated that the unusual stability of the uranium-arene interaction should be attributed to the formation of two $\delta$ bonds between uranium $5 \mathrm{f}_{\delta}$ orbitals and arene $\pi^{*}$ orbitals, which lie lower in energy than the nonbonding $5 f$ orbitals. $^{22,31,32}$ Inverse-sandwich diuranium arene complexes were employed as low valent uranium synthons to obtain novel compounds, ${ }^{25,26,33,34}$ which would otherwise be difficult to synthesize, as well as inspired the incorporation of arene in a supporting ligand framework, ${ }^{35,36}$ resulting in an unprecedented redox reactivity. ${ }^{4,5,37-39}$

However, despite the many precedents of inverse-sandwich diuranium arene complexes, ${ }^{3}$ and the close analogy between thorium and uranium, ${ }^{40-42}$ there is no example of an inversesandwich dithorium arene complex. Even thorium complexes of reduced arenes are rare: only three structurally characterized thorium reduced naphthalene complexes, in which $\mathrm{Th}(\mathrm{IV})$ was bound to a distorted naphthalene dianion in an $\eta^{4}$-mode, were reported by Gambarotta et al. ${ }^{43-45}$

We previously reported a series of inverse-sandwich rareearth metal biphenyl complexes $\left[\left(\mathrm{NN}^{\mathrm{TBS}}\right) \mathrm{M}\right]_{2}\left(\mu-\eta^{6}, \eta^{6}\right.$ $\left.\mathrm{C}_{6} \mathrm{H}_{5} \mathrm{Ph}\right)[\mathrm{K}(\text { solvent })]_{2} \quad\left(\mathbf{M}_{2}\right.$-biph-K,$\quad \mathrm{NN}^{\mathrm{TBS}}=\mathrm{fc}-$ $\left(\mathrm{NSi}^{t} \mathrm{BuMe}_{2}\right)_{2}, \mathrm{fc}=1,1^{\prime}$-ferrocenediyl, $\mathrm{M}=\mathrm{Sc}, \mathrm{Y}, \mathrm{La}, \mathrm{Lu}$,
Gd, Dy, Er $)^{18,19}$ and the inverse-sandwich diuranium toluene complex $\left[\left(\mathrm{NN}^{\mathrm{TBS}}\right) \mathrm{U}\right]_{2}\left(\mu-\eta^{6}, \eta^{6}-\mathrm{C}_{6} \mathrm{H}_{5} \mathrm{Me}\right)\left(\mathbf{U}_{2}\right.$-tol $){ }^{25}$ Encouraged by these results, we sought to pursue the analogous inverse-sandwich dithorium arene complexes. Herein, we report their synthesis and characterization together with reactivity studies and a computational analysis of their electronic structure and bonding interaction.

The $\mathrm{Th}(\mathrm{IV})$ precursor $\left(\mathrm{NN}^{\mathrm{TBS}}\right) \mathrm{ThCl}_{2}(\mathrm{THF})\left(\mathbf{T h C l}_{\mathbf{2}}\right)$ was prepared from $\mathrm{ThCl}_{4}(\mathrm{DME})_{2}$ and $\left(\mathrm{NN}^{\mathrm{TBS}}\right) \mathrm{K}_{2}\left(\mathrm{OEt}_{2}\right)^{46}$ (Scheme 1a). Following the protocol for $\mathbf{Y}_{\mathbf{2}}$-biph- $\mathbf{K}_{2}{ }^{18}$ the addition of 2.5 equiv of $\mathrm{KC}_{8}$ into a precooled THF solution of an equivalent of $\mathrm{ThCl}_{2}$ and 0.5 equiv of biphenyl at $-78{ }^{\circ} \mathrm{C}$ resulted in an immediate color change to black (Scheme $1 \mathrm{~b}$ ). The ${ }^{1} \mathrm{H}$ NMR spectrum of the crude reaction mixture showed diamagnetic peaks similar to those of $\mathbf{Y}_{\mathbf{2}}$-biph-K $\mathbf{K}_{2}{ }^{18} \mathrm{X}$-ray crystallography confirmed the product to be $\left[\left(\mathrm{NN}^{\mathrm{TBS}}\right) \mathrm{Th}\right.$ (THF) $]_{2}\left(\mu-\eta^{6}, \eta^{6}-\mathrm{C}_{6} \mathrm{H}_{5} \mathrm{Ph}\right)\left(\mathbf{T h}_{\mathbf{2}}\right.$-biph $)$. The other $\mathbf{T h}_{2}$-arene complexes were prepared analogously $\left(\mathbf{T h}_{\mathbf{2}}-\mathbf{n a p h}, \mathbf{T h}_{\mathbf{2}}\right.$ benzene, $\mathbf{T h}_{\mathbf{2}}$-tol, Scheme 1c-e).

All $\mathbf{T h}_{\mathbf{2}}$-arene compounds feature an inverse-sandwich structure with both thorium ions bound to the same phenyl ring in a symmetric $\mu-\eta^{6}, \eta^{6}$-fashion ( $\mathbf{T h}_{2}$-benzene, Figure S34; $\mathbf{T h}_{\mathbf{2}}$-tol, Figure S35; $\mathbf{T h}_{\mathbf{2}}$-biph, Figure S36; $\mathbf{T h}_{\mathbf{2}}$-naph, Figure S37). The structures of $\mathbf{T} \mathbf{h}_{\mathbf{2}}$-tol and $\mathbf{T} \mathbf{h}_{\mathbf{2}}$-naph are shown as representatives (Figure 1) and will be discussed for comparison. For $\mathbf{T h}_{\mathbf{2}}$-tol, the average $\mathrm{Th}-\mathrm{C}_{\text {ring }}$ distance of

Received: October 27, 2020 
Scheme 1. Synthesis of (a) $\mathrm{ThCl}_{2}$; (b) $\mathrm{Th}_{2}$-biph; (c) $\mathrm{Th}_{2}$ naph; (d) $\mathrm{Th}_{2}$-benzene; (e) $\mathrm{Th}_{2}$-tol
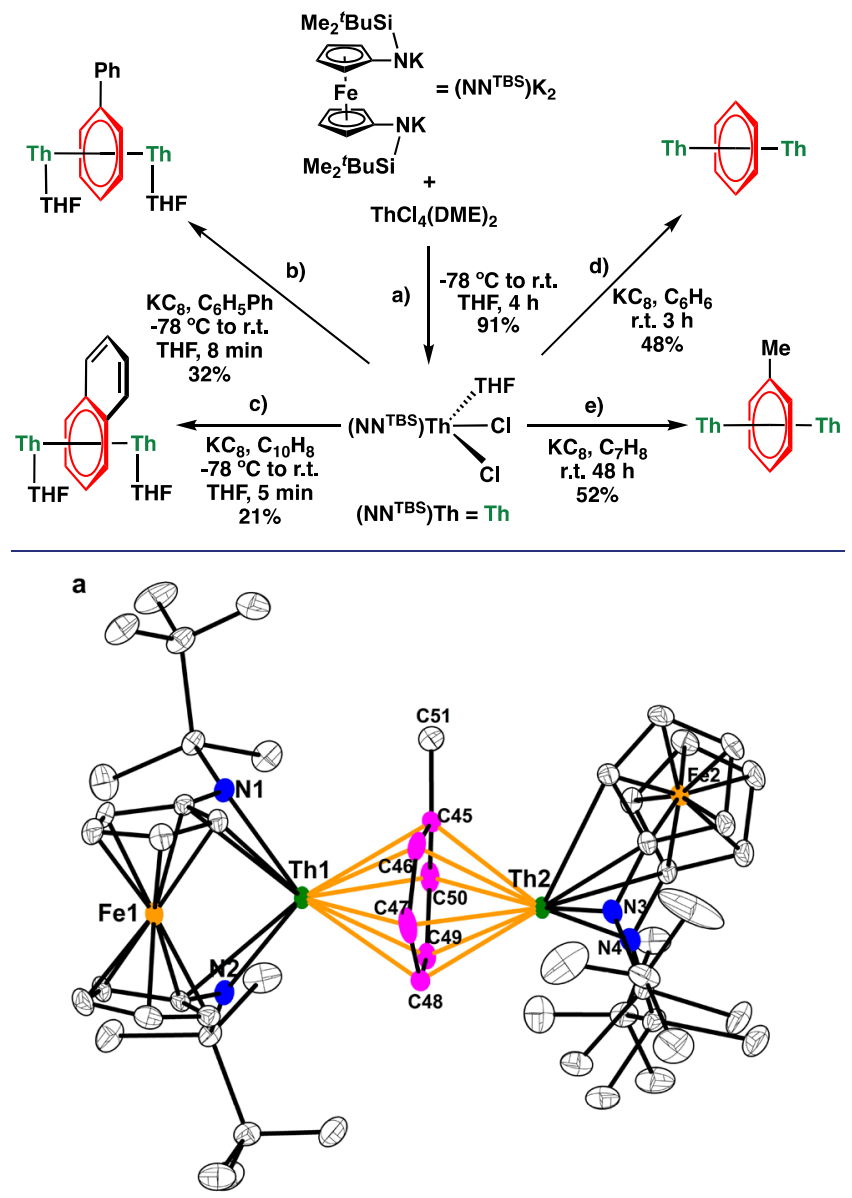

b

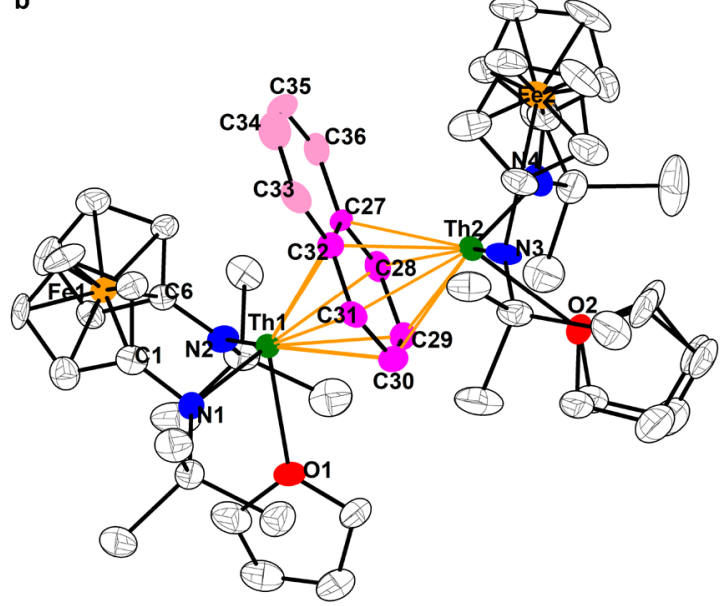

Figure 1. Thermal-ellipsoid ( $50 \%$ probability) representations of $\mathbf{T h}_{\mathbf{2}^{-}}$ tol (a) and $\mathbf{T h}_{2}$-naph (b). Hydrogen atoms were omitted for clarity.

$2.62 \AA$ and the average $\mathrm{Th}-\mathrm{C}_{\text {centroid }}$ distance of $2.18 \AA$ are comparable to the corresponding values in $\mathbf{U}_{\mathbf{2}}$-tol ${ }^{25}$ when taking account of the difference between their ionic radii. ${ }^{47}$ The $\mathrm{C}-\mathrm{C}$ distances of the bound ring range from $1.441(7)$ to 1.459 (7) $\AA$ with an average of $1.45 \AA$. These values are close to those of $\mathrm{U}_{2}$-tol (1.44(1) to 1.47(1) $\AA$ with an average of 1.45 $\AA){ }^{25}$ The average $\mathrm{Th}-\mathrm{N}$ distance of $2.37 \AA$ is $0.10 \AA$ longer than that of $2.27 \AA$ in $\mathbf{T h C l}$, but comparable to the average $\mathrm{U}-\mathrm{N}$ distance of $2.31 \AA$ in $\mathrm{U}_{2}$-tol. ${ }^{25}$ This elongation was also observed in $\mathbf{Y}_{2}$-biph- $\mathbf{K}_{2}$, when it was attributed to the weakening of the $\mathrm{Y}-\mathrm{N}$ bond rather than a change in the metal's oxidation state. ${ }^{18}$ In addition, a close contact between the ferrocene backbone and thorium was present in $\mathbf{T} \mathbf{h}_{\mathbf{2}}$-tol, indicating a donor-acceptor type interaction between these fragments. $^{48}$

Despite crystallizing with a coordinating THF molecule per thorium, the structural parameters for $\mathbf{T h}_{\mathbf{2}}$-naph resemble those of $\mathbf{T h}_{\mathbf{2}}$-tol. An intriguing feature is the alternating $\mathrm{C}-\mathrm{C}$ distances of the unbound ring (1.454(1), 1.351(1), 1.429(1), $1.357(1)$, and $1.437(1) \AA)$, implying a diene-like character, in accord with the distinct ${ }^{13} \mathrm{C}$ NMR chemical shifts of the unbound ring carbon atoms at 125.6 and 98.9 ppm. A similar dearomatization was observed in inverse-sandwich diuranium naphthalene complexes. ${ }^{21}$ The $\mathrm{Th}-\mathrm{C}_{\text {centroid }}$ distances for $\mathbf{T h}_{\mathbf{2}}$ arene, ranging from 2.177 to $2.241 \AA$, are much shorter than those for Th(IV) neutral arene complexes (2.655 to $2.95 \AA$ ), and also shorter than those of 2.463(7) and 2.497(7) $\AA$ in the thorium complexes with partially reduced arene backbones. In addition, the average $\mathrm{Th}-\mathrm{C}$ distances of $2.62-2.65 \AA$ in $\mathbf{T h}_{\mathbf{2}}$ arene are significantly shorter than the average $\mathrm{Th}-\mathrm{C}$ distances of $2.72-2.73 \AA$ in mononuclear $\mathrm{Th}(\mathrm{IV})$ reduced naphthalene complexes. ${ }^{43,44}$ Overall, the $\mathrm{Th}$-arene interaction in $\mathbf{T h}_{\mathbf{2}}$-arene should be stronger than that in previously reported thorium arene complexes ${ }^{43-45}$ but comparable to that in the inverse-sandwich diuranium ${ }^{3}$ and rare-earth metal arene complexes. $^{18}$

Spectroscopic data also agreed with the electronic structure of tetraanionic arenes and thorium(IV). The ${ }^{1} \mathrm{H}$ and ${ }^{13} \mathrm{C}$ NMR spectra of $\mathbf{T h}_{\mathbf{2}}$-arene displayed signals in the diamagnetic region, implying a closed-shell ground state. Chemical shifts of ${ }^{13} \mathrm{C}$ NMR spectra assigned to the coordinating phenyl ring in $\mathbf{T h}_{\mathbf{2}}$-arene complexes $\left(\mathbf{T h}_{\mathbf{2}}\right.$-benzene: $78.6 \mathrm{ppm} ; \mathbf{T h}_{\mathbf{2}}$-tol: 88.4, 85.1, 80.8, 80.6 ppm; Th $_{2}$-biph: 82.0, 77.5, 69.5, 66.1 ppm; Th ${ }_{2}$-naph: $76.2,73.8,69.4 \mathrm{ppm}$ ) are at higher fields compared to those of neutral arenes (for example, $128.6 \mathrm{ppm}$ for benzene and 137.9, 129.3, 128.56, $125.7 \mathrm{ppm}$ for toluene), indicating a highly reduced nature of the arene ligands in $\mathbf{T h}_{\mathbf{2}}$-arene. Moreover, the ${ }^{13} \mathrm{C}$ NMR chemical shifts of the bound phenyl ring in $\mathbf{T} \mathbf{h}_{2}$-arene were similar to those of $\mathbf{Y}_{\mathbf{2}}$-biph- $\mathbf{K}_{2}$, ${ }^{18}$ implying the arenes were quadruply reduced (Table S1). The UV-vis-NIR absorption spectra of $\mathbf{T h}_{\mathbf{2}}$-arene showed a broad and intense band between 400 and $600 \mathrm{~nm}$ (Figures S46-51); however, no characteristic peaks of $\mathrm{Th}$ (III) around 700 and $800 \mathrm{~nm}$ were observed. ${ }^{49}$ Furthermore, X-ray photoelectron spectroscopy (Table S2) and the absence of an electron paramagnetic resonance signal also support a formal oxidation state of +4 for thorium in $\mathbf{T h} \mathbf{h}_{2}$-arene.

It is worth mentioning that $\mathbf{T} \mathbf{h}_{\mathbf{2}}$-benzene is the first metal complex that contains the parent tetranionic benzene, which is the prototypical $6 \mathrm{C}, 10 \pi$-electron aromatic system. ${ }^{50}$ In addition, the fact that the arene rather than thorium was reduced during the formation of $\mathbf{T} \mathbf{h}_{\mathbf{2}}$-arene is also in line with the formation of $\mathbf{M}_{2}-\mathbf{b i p h}-\mathrm{K}_{\mathbf{2}}(\mathrm{M}=\mathrm{Sc}, \mathrm{Y}, \mathrm{La}, \mathrm{Lu}, \mathrm{Gd}, \mathrm{Dy}, \mathrm{Er}$, $\mathrm{Sm}) .^{51,52}$

Arene exchange reactions were previously observed in inverse-sandwich diuranium arene complexes. ${ }^{20,22,32}$ Arene exchange is also accessible with $\mathbf{T} \mathbf{h}_{2}$-arene and we observed a slow exchange when heating $\mathbf{T} \mathbf{h}_{\mathbf{2}}$-benzene or $\mathbf{T} \mathbf{h}_{2}$-tol in $\mathrm{C}_{6} \mathrm{D}_{6}$, while no exchange was observed for $\mathbf{T h}_{2}$-benzene in $\mathrm{C}_{7} \mathrm{D}_{8}$ or $\mathbf{T h}_{2}$-biph in $\mathrm{C}_{6} \mathrm{D}_{6}$. A competitive reaction to synthesize $\mathbf{T h}_{\mathbf{2}^{-}}$ benzene and $\mathbf{T h}_{\mathbf{2}}$-tol starting with an equal molar mixture of 
benzene and toluene resulted in a product ratio of 10:1 for $T h_{2}$-benzene and $T h_{2}$-tol.

For $\mathbf{T h}_{2}$-naph, a rapid exchange with $\mathrm{C}_{6} \mathrm{D}_{6}$ was observed (Scheme $2 \mathrm{a}$ ). This result seems counterintuitive since benzene

Scheme 2. Arene Exchange Reactions and Reactivity Studies of $\mathrm{Th}_{2}$-arene

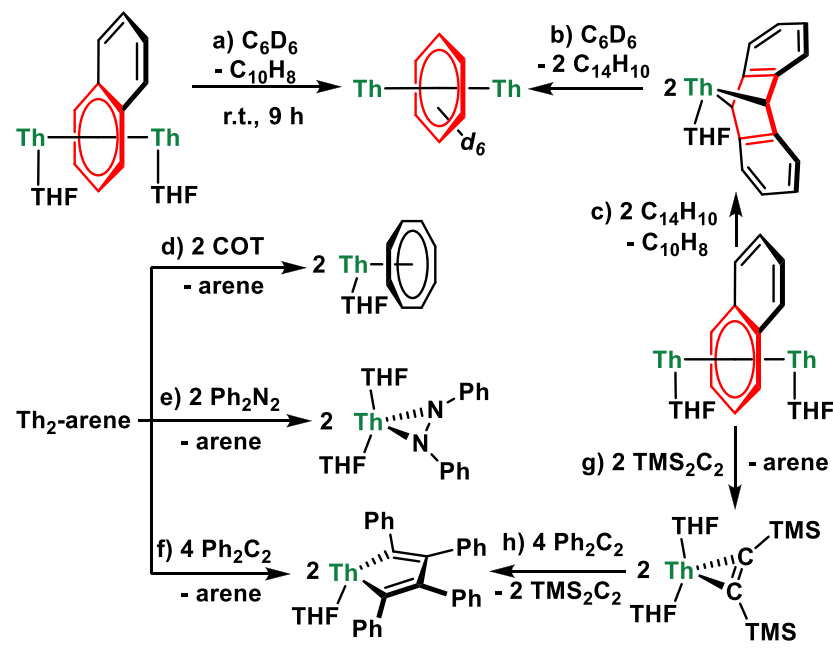

is considered more difficult to reduce than naphthalene based on their reduction potentials. However, the dearomatization of the unbound ring in $\mathbf{T} \mathbf{h}_{\mathbf{2}}$-naph may account for this abnormal reactivity. Moreover, an arene exchange was observed between $\mathbf{T} \mathbf{h}_{\mathbf{2}}$-naph and biphenyl and between $\mathbf{T h}_{\mathbf{2}}$-tol and biphenyl. Therefore, the arene exchange study established the stability of $T h_{2}$-arene as $T h_{2}$-naph $\ll T h_{2}$-tol $<T h_{2}$-benzene $\approx T h_{2^{-}}$ biph.

The low stability of $\mathbf{T} \mathbf{h}_{\mathbf{2}}$-naph prompted us to investigate the reduction of $\mathbf{T h C l}_{2}$ in the presence of anthracene, which is known to form a stable dianion upon reduction. ${ }^{1}$ This reaction led to the formation of a mononuclear thorium complex of dianionic anthracene, $\left[\left(\mathrm{NN}^{\mathrm{TBS}}\right) \mathrm{Th}(\mathrm{THF})\right]\left(9,10-\eta^{2}-\mathrm{C}_{14} \mathrm{H}_{10}\right)$ (Th-anth). Intriguingly, when heating in $\mathrm{C}_{6} \mathrm{D}_{6}, \mathrm{Th}$-anth reduced benzene to form $\mathbf{T h}_{\mathbf{2}}$-benzene (Scheme $2 \mathrm{~b}$ ). To the best of our knowledge, this is the first confirmed benzene reduction by a well-defined metal anthracene complex, although such compounds were proposed as intermediates. ${ }^{27}$ While the reverse reaction of $\mathbf{T} \mathbf{h}_{\mathbf{2}}$-benzene and anthracene did not take place, $\mathbf{T} \mathbf{h}_{\mathbf{2}}$-naph could reduce anthracene to yield $\mathbf{T h}$ anth (Scheme 2c). The arene exchange reactivity highlights the higher stability for nonfused arenes over more readily reducible fused arenes in the inverse-sandwich dithorium arene complexes.

We also explored the reactivity of $\mathbf{T h}_{2}$-arene toward unsaturated substrates. $\mathbf{T} \mathbf{h}_{2}$-arene functioned as four-electron reductants to reduce cyclooctatetraene (Scheme $2 \mathrm{~d}$ ) or azobenzene (Scheme 2e) to form $\left(\mathrm{NN}^{\mathrm{TBS}}\right) \mathrm{Th}(\mathrm{THF})\left(\eta^{8}\right.$ COT) (Th-COT) or $\left(\mathrm{NN}^{\mathrm{TBS}}\right) \mathrm{Th}(\mathrm{THF})_{2}\left(\eta^{2}-\mathrm{N}_{2} \mathrm{Ph}_{2}\right)$ (Th$\mathbf{N}_{\mathbf{2}} \mathbf{P h _ { 2 }}$ ), respectively, in a similar fashion as the inversesandwich diuranium arene complexes. ${ }^{20,21,23}$ The outcome of the alkyne reduction reactions were dependent on the nature of the alkyne. While all $\mathbf{T h}_{\mathbf{2}}$-arene could reduce diphenylacetylene (Scheme 2f) to form a five-membered metallocycle $\left(\mathrm{NN}^{\mathrm{TBS}}\right) \mathrm{Th}(\mathrm{THF})\left(\eta^{2}-\mathrm{C}_{4} \mathrm{Ph}_{4}\right)\left(\mathbf{T h}-\mathbf{C}_{4} \mathbf{P h}_{4}\right)$, the reduction of bis(trimethylsilyl)acetylene took place only with the most reactive $\mathbf{T h}_{\mathbf{2}}$-naph (Scheme $2 \mathrm{~g}$ ) and resulted in the formation of a rare actinide metallacyclopropene, ${ }^{53-55}\left(\mathrm{NN}^{\mathrm{TBS}}\right) \mathrm{Th}$ $(\mathrm{THF})_{2}\left(\eta^{2}-\mathrm{C}_{2}\left(\mathrm{SiMe}_{3}\right)_{2}\right)$, which could further react with diphenylacetylene to generate $\mathbf{T h}-\mathrm{C}_{4} \mathbf{P h}_{4}$ (Scheme $2 \mathrm{~h}$ ).

Density functional theory (DFT) calculations of $\mathbf{T h}_{\mathbf{2}}$-arene show that the highest occupied molecular orbital (HOMO) and HOMO-1 of $\mathbf{T h}_{\mathbf{2}}$-benzene (Figure 2; see Figures S60-62
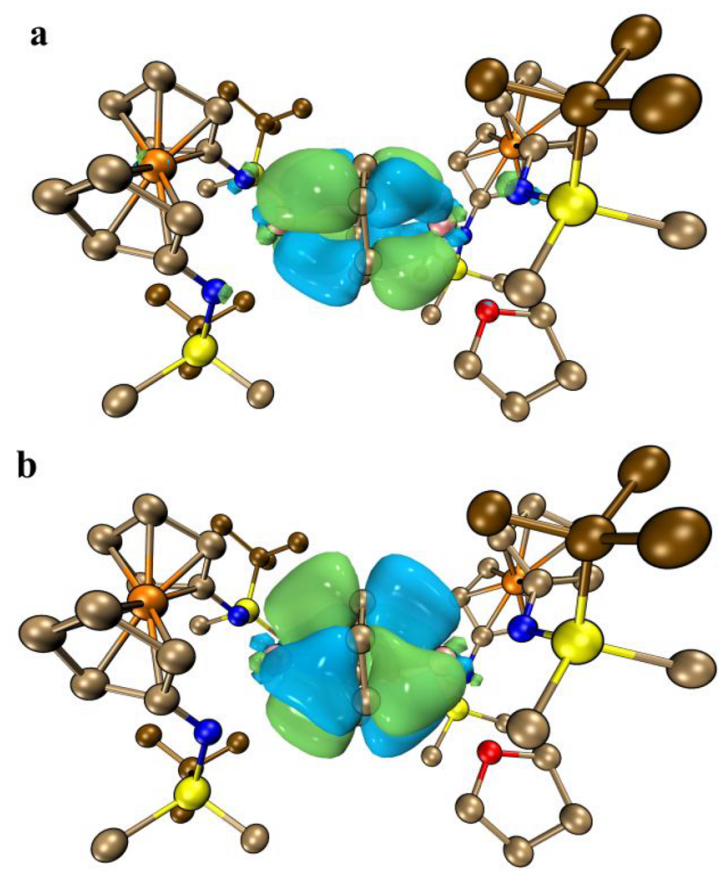

Figure 2. HOMO and HOMO-1 (isovalue 0.03 ) of $\mathbf{T h}_{2}$-benzene. Hydrogen atoms are omitted for clarity.

for other $\mathbf{T} \mathbf{h}_{2}$-arene) are close in energy $(-4.04$ and $-4.07 \mathrm{eV}$, Table S3). They feature $\delta$-type bonding orbitals composed of the $\pi_{4}$ and $\pi_{5}$ orbitals of benzene and the $6 \mathrm{~d}_{\delta}$ and $5 \mathrm{f}_{\delta}$ orbitals of thorium. A composition analysis showed that the contributions from benzene-based orbitals are $66.5 \%$ and $67.4 \%$, while those from thorium orbitals are $28.2 \%$ (6d: $15.8 \%$; $5 \mathrm{f}: 12.4 \%$ ) and 28.7\% (6d: 16.9\%; 5f: $11.8 \%$ ) for HOMO and HOMO-1, respectively. The HOMO and HOMO-1 of $\mathbf{T h}_{\mathbf{2}}$-tol and $\mathbf{T h}_{\mathbf{2}}$ biph share similar energy levels and orbital compositions as $\mathbf{T h}_{\mathbf{2}}$-benzene (Tables S9 and S10). However, the HOMO of $\mathrm{Th}_{2}$-naph $(-3.44 \mathrm{eV})$ is $0.36 \mathrm{eV}$ higher in energy than HOMO-1 and also significantly higher than the HOMOs of other $\mathbf{T h}_{\mathbf{2}}$-arene, which may explain the low stability of $\mathbf{T h}_{\mathbf{2}}$ naph (Table S11). In addition, the Mulliken population analysis showed that the charge of the bound ring in $\mathbf{T h}_{\mathbf{2}}$-naph $(-0.66)$ differs from those in other $\mathbf{T h}_{2}$-arene $(-1.30$ to -1.61) (Table S12). Furthermore, the Wiberg Th-C bond orders in $\mathbf{T h}_{\mathbf{2}}$-arene (Table S13) are $0.53-0.58$; the average $\mathrm{C}-\mathrm{C}$ bond orders for the bound rings are $1.17-1.23$. The latter values are much weaker than the bond orders of the corresponding free arenes (1.49-1.58) (Table S14). These values indicate a strong interaction between thorium and arenes and a significant weakening of the $\mathrm{C}-\mathrm{C}$ bonds of the bound ring, consistent with the presence of $\delta$ bonding interactions. Notably, the bond orders of the unbound ring in $T \mathbf{h}_{2}$-naph have different values of $1.27,1.69,1.42,1.69$, and 1.27 , consistent with the structural parameters for a diene-like character. 
We also compared the $\delta$ bonding interactions in $\mathbf{T} \mathbf{h}_{\mathbf{2}}$-arene with those in the inverse-sandwich diuranium and rare-earth metal arene complexes. The contributions from thorium orbitals in $\delta$ bonds are slightly under 30\%, in between the values for $\mathbf{Y}_{2}$-biph- $\mathbf{K}_{2}$ (ca. $20 \% \mathrm{Y}$ orbitals) ${ }^{18}$ and those of inverse-sandwich diuranium arene complexes (ca. $50 \% \mathrm{U}$ orbitals). ${ }^{22,32}$ These values indicate that the thorium-arene interaction is more covalent than the rare-earth metal-arene interaction but less covalent than the uranium-arene interaction, in line with the general trend of covalency for $f$ elements. Moreover, the contribution of Th $6 \mathrm{~d}$ orbitals is higher than that of $5 \mathrm{f}$ orbitals, in contrast to the case of the inverse-sandwich diuranium arene complexes, in which the contribution of $\mathrm{U} 5 \mathrm{f}$ orbitals is more than double that of $6 \mathrm{~d}$ orbitals. $^{22}$ This trend is in accordance with the relative energies for actinide $6 \mathrm{~d}$ and $5 \mathrm{f}$ orbitals. ${ }^{56}$

In summary, we synthesized and characterized the first inverse-sandwich dithorium arene-bridged complexes with benzene, toluene, biphenyl, and naphthalene. The structural and spectroscopic parameters are consistent with a bridged tetraanionic arene and thorium(IV) centers, analogous to our findings for the corresponding bridged tetranionic arene rareearth metal complexes. The arene exchange reaction established the relative stability of $\mathbf{T h}_{2}$-arene, and reactivity studies showed their use as low valent thorium synthons. DFT calculations unveiled the presence of a $\delta$ bonding interaction in these compounds, in analogy to relevant uranium and rareearth metal complexes. These compounds possess high synthetic utility, in particular, enabling multielectron redox chemistry for thorium. Moreover, they provide insight into the electronic structures of thorium complexes in comparison to those of uranium and rare-earth metals. Further reactivity studies and an in-depth analysis of the electronic structure and bonding interactions of $\mathbf{T h}_{\mathbf{2}}$-arene are currently ongoing.

\section{ASSOCIATED CONTENT}

\section{(s) Supporting Information}

The Supporting Information is available free of charge at https://pubs.acs.org/doi/10.1021/jacs.0c11215.

Synthetic procedures, NMR spectra, and other characterizations and DFT calculation details (PDF)

\section{AUTHOR INFORMATION}

\section{Corresponding Authors}

Paula L. Diaconescu - Department of Chemistry \& Biochemistry, University of California, Los Angeles, California 90095, United States; (1) orcid.org/0000-00032732-4155; Email: pld@chem.ucla.edu

Wenliang Huang - Beijing National Laboratory for Molecular Sciences, State Key Laboratory of Rare Earth Material Chemistry and Application, Radiochemistry and Radiation Chemistry Key Laboratory of Fundamental Science, College of Chemistry and Molecular Engineering, Peking University, Beijing 100871, P. R. China; (1) orcid.org/0000-0003-00568256; Email: wlhuang@pku.edu.cn

\section{Authors}

Chao Yu - Beijing National Laboratory for Molecular Sciences, State Key Laboratory of Rare Earth Material Chemistry and Application, Radiochemistry and Radiation Chemistry Key Laboratory of Fundamental Science, College of Chemistry and Molecular Engineering, Peking University,
Beijing 100871, P. R. China; 이이이.org/0000-0002-69588004

Jiefeng Liang - Beijing National Laboratory for Molecular Sciences, State Key Laboratory of Rare Earth Material Chemistry and Application, Radiochemistry and Radiation Chemistry Key Laboratory of Fundamental Science, College of Chemistry and Molecular Engineering, Peking University, Beijing 100871, P. R. China; (1) orcid.org/0000-0003-08263158

Chong Deng - Beijing National Laboratory for Molecular Sciences, State Key Laboratory of Rare Earth Material Chemistry and Application, Radiochemistry and Radiation Chemistry Key Laboratory of Fundamental Science, College of Chemistry and Molecular Engineering, Peking University, Beijing 100871, P. R. China; 이이이.org/0000-0001-83201569

Guillaume Lefèvre - i-CLeHS CSB2D, CNRS/Chimie ParisTech, 75005 Paris, France; ○ orcid.org/0000-00019409-5861

Thibault Cantat - Université Paris-Saclay, 91191 Gif-surYvette, Cedex, France; (ㅇ) orcid.org/0000-0001-5265-8179

Complete contact information is available at:

https://pubs.acs.org/10.1021/jacs.0c11215

\section{Funding}

C.Y., J.L., C.D., and W.H. thank Beijing National Laboratory for Molecular Sciences and Peking University for funding. C.Y. was supported by a Beijing National Laboratory for Molecular Sciences Postdoctoral Fellowship. The High-Performance Computing Platform of Peking University is acknowledged for providing access to computational resources. T.C. thanks CEA and CNRS for support. P.L.D. acknowledges support from NSF Grant CHE-1809116.

\section{Notes}

The authors declare no competing financial interest.

The crystal structures were deposited with the Cambridge Crystallographic Data Centre (CCDC) with deposition numbers 2031028-2031037.

\section{ACKNOWLEDGMENTS}

We thank Dr. Jie Su for help with X-ray crystallography and Dr. Hui $\mathrm{Fu}$ and Dr. Xiu Zhang for help with NMR spectroscopy.

\section{REFERENCES}

(1) Bochkarev, M. N. Synthesis, Arrangement, and Reactivity of Arene-Lanthanide Compounds. Chem. Rev. 2002, 102 (6), 20892118.

(2) Huang, W.; Diaconescu, P. L. Chapter 266 - Rare Earth AreneBridged Complexes Obtained by Reduction of Organometallic Precursors. In Handbook on the Physics and Chemistry of Rare Earths; Bünzli, J.-C. G., Pecharsky, V. K., Eds.; Elsevier: 2014; Vol. 45, pp $261-329$.

(3) Liddle, S. T. Inverted sandwich arene complexes of uranium. Coord. Chem. Rev. 2015, 293-294, 211-227.

(4) Halter, D. P.; Heinemann, F. W.; Bachmann, J.; Meyer, K. Uranium-mediated electrocatalytic dihydrogen production from water. Nature 2016, 530 (7590), 317-321.

(5) Halter, D. P.; Heinemann, F. W.; Maron, L.; Meyer, K. The role of uranium-arene bonding in $\mathrm{H}_{2} \mathrm{O}$ reduction catalysis. Nat. Chem. 2018, 10 (3), 259-267.

(6) Mazzanti, M. The secret is in the ring. Nat. Chem. 2018, 10 (3), 247-249. 
(7) Halter, D. P.; Palumbo, C. T.; Ziller, J. W.; Gembicky, M.; Rheingold, A. L.; Evans, W. J.; Meyer, K. Electrocatalytic $\mathrm{H}_{2} \mathrm{O}$ Reduction with f-Elements: Mechanistic Insight and Overpotential Tuning in a Series of Lanthanide Complexes. J. Am. Chem. Soc. 2018, 140 (7), 2587-2594.

(8) La Pierre, H. S.; Scheurer, A.; Heinemann, F. W.; Hieringer, W.; Meyer, K. Synthesis and Characterization of a Uranium(II) Monoarene Complex Supported by $\delta$ Backbonding. Angew. Chem., Int. Ed. 2014, 53 (28), 7158-7162.

(9) Billow, B. S.; Livesay, B. N.; Mokhtarzadeh, C. C.; McCracken, J.; Shores, M. P.; Boncella, J. M.; Odom, A. L. Synthesis and Characterization of a Neutral U(II) Arene Sandwich Complex. J. Am. Chem. Soc. 2018, 140 (50), 17369-17373.

(10) Fieser, M. E.; Palumbo, C. T.; La Pierre, H. S.; Halter, D. P.; Voora, V. K.; Ziller, J. W.; Furche, F.; Meyer, K.; Evans, W. J. Comparisons of lanthanide/actinide +2 ions in a tris(aryloxide)arene coordination environment. Chem. Sci. 2017, 8 (11), 7424-7433.

(11) Palumbo, C. T.; Halter, D. P.; Voora, V. K.; Chen, G. P.; Chan, A. K.; Fieser, M. E.; Ziller, J. W.; Hieringer, W.; Furche, F.; Meyer, K.; Evans, W. J. Metal versus Ligand Reduction in $\mathrm{Ln}^{3+}$ Complexes of a Mesitylene-Anchored Tris(Aryloxide) Ligand. Inorg. Chem. 2018, 57 (5), 2823-2833.

(12) Palumbo, C. T.; Halter, D. P.; Voora, V. K.; Chen, G. P.; Ziller, J. W.; Gembicky, M.; Rheingold, A. L.; Furche, F.; Meyer, K.; Evans, W. J. Using Diamagnetic Yttrium and Lanthanum Complexes to Explore Ligand Reduction and $\mathrm{C}-\mathrm{H}$ Bond Activation in a Tris(aryloxide)mesitylene Ligand System. Inorg. Chem. 2018, 57 (20), 12876-12884.

(13) Cassani, M. C.; Duncalf, D. J.; Lappert, M. F. The First Example of a Crystalline Subvalent Organolanthanum Complex: $\left[\mathrm{K}\left([18]\right.\right.$ crown-6)- $\left.\left(\eta^{2}-\mathrm{C}_{6} \mathrm{H}_{6}\right)_{2}\right]\left[\left(\mathrm{LaCp}^{\mathrm{tt}}{ }_{2}\right)_{2}\left(\mu-\eta^{6}: \eta^{6}-\mathrm{C}_{6} \mathrm{H}_{6}\right)\right] \bullet 2 \mathrm{C}_{6} \mathrm{H}_{6}$ $\left(\mathrm{Cp}^{\mathrm{tt}}=\eta^{5}-\mathrm{C}_{5} \mathrm{H}_{3} \mathrm{Bu}_{2}^{t}-1,3\right)$. J. Am. Chem. Soc. 1998, 120 (49), 1295812959.

(14) Kotyk, C. M.; Fieser, M. E.; Palumbo, C. T.; Ziller, J. W.; Darago, L. E.; Long, J. R.; Furche, F.; Evans, W. J. Isolation of + 2 rare earth metal ions with three anionic carbocyclic rings: bimetallic bis(cyclopentadienyl) reduced arene complexes of $\mathrm{La}^{2+}$ and $\mathrm{Ce}^{2+}$ are four electron reductants. Chem. Sci. 2015, 6 (12), 7267-7273.

(15) Kelly, R. P.; Maron, L.; Scopelliti, R.; Mazzanti, M. Reduction of a Cerium(III) Siloxide Complex To Afford a Quadruple-Decker Arene-Bridged Cerium(II) Sandwich. Angew. Chem., Int. Ed. 2017, 56 (49), 15663-15666.

(16) Palumbo, C. T.; Darago, L. E.; Dumas, M. T.; Ziller, J. W.; Long, J. R.; Evans, W. J. Structure, Magnetism, and Multi-electron Reduction Reactivity of the Inverse Sandwich Reduced Arene $\mathrm{La}^{2+}$ Complex $\left[\left\{\left[\mathrm{C}_{5} \mathrm{H}_{3}\left(\mathrm{SiMe}_{3}\right)_{2}\right]_{2} \mathrm{La}\right\}_{2}\left(\mu-\eta^{6}: \eta^{6}-\mathrm{C}_{6} \mathrm{H}_{6}\right)\right]^{1-}$. Organometallics 2018, 37 (19), 3322-3331.

(17) Kelly, R. P.; Toniolo, D.; Tirani, F. F.; Maron, L.; Mazzanti, M. A tetranuclear samarium(II) inverse sandwich from direct reduction of toluene by a samarium(II) siloxide. Chem. Commun. 2018, 54 (73), $10268-10271$.

(18) Huang, W.; Dulong, F.; Wu, T.; Khan, S. I.; Miller, J. T.; Cantat, T.; Diaconescu, P. L. A six-carbon $10 \pi$-electron aromatic system supported by group 3 metals. Nat. Commun. 2013, 4 (1), 1448.

(19) Huang, W.; Le Roy, J. J.; Khan, S. I.; Ungur, L.; Murugesu, M.; Diaconescu, P. L. Tetraanionic Biphenyl Lanthanide Complexes as Single-Molecule Magnets. Inorg. Chem. 2015, 54 (5), 2374-2382.

(20) Diaconescu, P. L.; Arnold, P. L.; Baker, T. A.; Mindiola, D. J.; Cummins, C. C. Arene-Bridged Diuranium Complexes: Inverted Sandwiches Supported by $\delta$ Backbonding. J. Am. Chem. Soc. 2000, 122 (25), 6108-6109.

(21) Diaconescu, P. L.; Cummins, C. C. Diuranium Inverted Sandwiches Involving Naphthalene and Cyclooctatetraene. J. Am. Chem. Soc. 2002, 124 (26), 7660-7661.

(22) Evans, W. J.; Kozimor, S. A.; Ziller, J. W.; Kaltsoyannis, N. Structure, Reactivity, and Density Functional Theory Analysis of the Six-Electron Reductant, $\left[\left(\mathrm{C}_{5} \mathrm{Me}_{5}\right)_{2} \mathrm{U}\right]_{2}\left(\mu-\eta^{6}: \eta^{6}-\mathrm{C}_{6} \mathrm{H}_{6}\right)$, Synthesized via a New Mode of $\left(\mathrm{C}_{5} \mathrm{Me}_{5}\right)_{3} \mathrm{M}$ Reactivity. J. Am. Chem. Soc. 2004, 126 (44), 14533-14547.

(23) Evans, W. J.; Traina, C. A.; Ziller, J. W. Synthesis of Heteroleptic Uranium $\left(\mu-\eta^{6}: \eta^{6}-\mathrm{C}_{6} \mathrm{H}_{6}\right)_{2}-$ Sandwich Complexes via Facile Displacement of $\left(\eta^{5}-\mathrm{C}_{5} \mathrm{Me}_{5}\right)^{1-}$ by Ligands of Lower Hapticity and Their Conversion to Heteroleptic Bis(imido) Compounds. J. Am. Chem. Soc. 2009, 131 (47), 17473-17481.

(24) Mills, D. P.; Moro, F.; McMaster, J.; van Slageren, J.; Lewis, W.; Blake, A. J.; Liddle, S. T. A delocalized arene-bridged diuranium single-molecule magnet. Nat. Chem. 2011, 3 (6), 454-460.

(25) Monreal, M. J.; Khan, S. I.; Kiplinger, J. L.; Diaconescu, P. L. Molecular quadrangle formation from a diuranium $\mu-\eta^{6}, \eta^{6}$-toluene complex. Chem. Commun. 2011, 47 (32), 9119-9121.

(26) Patel, D.; Moro, F.; McMaster, J.; Lewis, W.; Blake, A. J.; Liddle, S. T. A Formal High Oxidation State Inverse-Sandwich Diuranium Complex: A New Route to f-Block-Metal Bonds. Angew. Chem., Int. Ed. 2011, 50 (44), 10388-10392.

(27) Arnold, P. L.; Mansell, S. M.; Maron, L.; McKay, D. Spontaneous reduction and $\mathrm{C}-\mathrm{H}$ borylation of arenes mediated by uranium(III) disproportionation. Nat. Chem. 2012, 4 (8), 668-674.

(28) Diaconescu, P. L.; Cummins, C. C. $\mu-\eta^{6}, \eta^{6}$-Arene-Bridged Diuranium Hexakisketimide Complexes Isolable in Two States of Charge. Inorg. Chem. 2012, 51 (5), 2902-2916.

(29) Mougel, V.; Camp, C.; Pécaut, J.; Copéret, C.; Maron, L.; Kefalidis, C. E.; Mazzanti, M. Siloxides as Supporting Ligands in Uranium(III)-Mediated Small-Molecule Activation. Angew. Chem., Int. Ed. 2012, 51 (49), 12280-12284.

(30) Camp, C.; Mougel, V.; Pécaut, J.; Maron, L.; Mazzanti, M. Cation-Mediated Conversion of the State of Charge in Uranium Arene Inverted-Sandwich Complexes. Chem. - Eur. J. 2013, 19 (51), $17528-17540$.

(31) Patel, D.; Tuna, F.; McInnes, E. J. L.; McMaster, J.; Lewis, W.; Blake, A. J.; Liddle, S. T. A triamido-uranium(V) inverse-sandwich $10 \pi$-toluene tetraanion arene complex. Dalton Trans 2013, 42 (15), 5224-5227.

(32) Vlaisavljevich, B.; Diaconescu, P. L.; Lukens, W. L.; Gagliardi, L.; Cummins, C. C. Investigations of the Electronic Structure of Arene-Bridged Diuranium Complexes. Organometallics 2013, 32 (5), $1341-1352$.

(33) Wooles, A. J.; Mills, D. P.; Tuna, F.; McInnes, E. J. L.; Law, G. T. W.; Fuller, A. J.; Kremer, F.; Ridgway, M.; Lewis, W.; Gagliardi, L.; Vlaisavljevich, B.; Liddle, S. T. Uranium(III)-carbon multiple bonding supported by arene $\delta$-bonding in mixed-valence hexauranium nanometre-scale rings. Nat. Commun. 2018, 9 (1), 2097.

(34) Patel, D.; McMaster, J.; Lewis, W.; Blake, A. J.; Liddle, S. T. Reductive assembly of cyclobutadienyl and diphosphacyclobutadienyl rings at uranium. Nat. Commun. 2013, 4 (1), 2323.

(35) Bart, S. C.; Heinemann, F. W.; Anthon, C.; Hauser, C.; Meyer, K. A New Tripodal Ligand System with Steric and Electronic Modularity for Uranium Coordination Chemistry. Inorg. Chem. 2009, 48 (19), 9419-9426.

(36) Fortier, S.; Aguilar-Calderón, J. R.; Vlaisavljevich, B.; MettaMagaña, A. J.; Goos, A. G.; Botez, C. E. An N-Tethered Uranium(III) Arene Complex and the Synthesis of an Unsupported U-Fe Bond. Organometallics 2017, 36 (23), 4591-4599.

(37) Lam, O. P.; Bart, S. C.; Kameo, H.; Heinemann, F. W.; Meyer, $\mathrm{K}$. Insights into the mechanism of carbonate formation through reductive cleavage of carbon dioxide with low-valent uranium centers. Chem. Commun. 2010, 46 (18), 3137-3139.

(38) La Pierre, H. S.; Kameo, H.; Halter, D. P.; Heinemann, F. W.; Meyer, K. Coordination and Redox Isomerization in the Reduction of a Uranium(III) Monoarene Complex. Angew. Chem., Int. Ed. 2014, 53 (28), 7154-7157.

(39) Yadav, M.; Metta-Magaña, A.; Fortier, S. Intra- and intermolecular interception of a photochemically generated terminal uranium nitride. Chem. Sci. 2020, 11 (9), 2381-2387.

(40) Hayton, T. W. Recent developments in actinide-ligand multiple bonding. Chem. Commun. 2013, 49 (29), 2956-2973. 
(41) Arnold, P. L.; Turner, Z. R. Carbon oxygenate transformations by actinide compounds and catalysts. Nat. Rev. Chem. 2017, 1 (1), 0002.

(42) Hayton, T. W.; Kaltsoyannis, N. Organometallic Actinide Complexes with Novel Oxidation States and Ligand Types. In Experimental and Theoretical Approaches to Actinide Chemistry; Gibson, J. K., Jong, W. A., Eds.; John Wiley \& Sons, Inc.: Hoboken, NJ, 2018; pp 181-236.

(43) Korobkov, I.; Gambarotta, S.; Yap, G. P. A. The First Thorium Arene Complex: A Divalent Synthon. Angew. Chem., Int. Ed. 2003, 42 (7), 814-818.

(44) Korobkov, I.; Gambarotta, S.; Yap, G. P. A. Amide from Dinitrogen by In Situ Cleavage and Partial Hydrogenation Promoted by a Transient Zero-Valent Thorium Synthon. Angew. Chem., Int. Ed. 2003, 42 (40), 4958-4961.

(45) Korobkov, I.; Gambarotta, S. Cis Double Addition of $\mathrm{CO}_{2}$ to a Coordinated Arene of a Thorium Complex. Organometallics 2004, 23 (23), 5379-5381.

(46) Monreal, M. J.; Carver, C. T.; Diaconescu, P. L. Redox Processes in a Uranium $\mathrm{Bis}(1,1$ '-diamidoferrocene) Complex. Inorg. Chem. 2007, 46 (18), 7226-7228.

(47) Shannon, R. D. Revised effective ionic radii and systematic studies of interatomic distances in halides and chalcogenides. Acta Crystallogr., Sect. A: Cryst. Phys., Diffr., Theor. Gen. Crystallogr. 1976, $32(5), 751-767$.

(48) Huang, W.; Diaconescu, P. L. Reactivity and Properties of Metal Complexes Enabled by Flexible and Redox-Active Ligands with a Ferrocene Backbone. Inorg. Chem. 2016, 55 (20), 10013-10023.

(49) Parry, J. S.; Cloke; Coles, S. J.; Hursthouse, M. B. Synthesis and Characterization of the First Sandwich Complex of Trivalent Thorium: A Structural Comparison with the Uranium Analogue. J. Am. Chem. Soc. 1999, 121 (29), 6867-6871.

(50) Huang, W.; Diaconescu, P. L. Rare-earth metal $\pi$-complexes of reduced arenes, alkenes, and alkynes: bonding, electronic structure, and comparison with actinides and other electropositive metals. Dalton Trans 2015, 44 (35), 15360-15371.

(51) Huang, W.; Brosmer, J. L.; Diaconescu, P. L. In situ synthesis of lanthanide complexes supported by a ferrocene diamide ligand: extension to redox-active lanthanide ions. New J. Chem. 2015, 39, 7696-7702.

(52) Xiao, Y.; Zhao, X.-K.; Wu, T.; Miller, J. T.; Hu, H.-S.; Li, J.; Huang, W.; Diaconescu, P. L. Distinct electronic structures and bonding interactions in inverse-sandwich samarium and ytterbium biphenyl complexes. Chem. Sci. 2020, DOI: 10.1039/D0SC03555F.

(53) Fang, B.; Ren, W.; Hou, G.; Zi, G.; Fang, D.-C.; Maron, L.; Walter, M. D. An Actinide Metallacyclopropene Complex: Synthesis, Structure, Reactivity, and Computational Studies. J. Am. Chem. Soc. 2014, 136 (49), 17249-17261.

(54) Zhang, L.; Hou, G.; Zi, G.; Ding, W.; Walter, M. D. Influence of the $5 f$ Orbitals on the Bonding and Reactivity in Organoactinides: Experimental and Computational Studies on a Uranium Metallacyclopropene. J. Am. Chem. Soc. 2016, 138 (15), 5130-5142.

(55) $\mathrm{Zi}$, G. Recent developments in actinide metallacycles. Chem. Commun. 2018, 54 (54), 7412-7430.

(56) Bursten, B. E.; Rhodes, L. F.; Strittmatter, R. J. The bonding in $\operatorname{tris}\left(\eta^{5}\right.$-cyclopentadienyl) actinide complexes IV: Electronic structural effects in $\mathrm{AnCl}_{3}$ and $\left(\eta^{5}-\mathrm{C}_{5} \mathrm{H}_{5}\right)_{3} \mathrm{An}(\mathrm{An}=\mathrm{Th}-\mathrm{Cf})$ complexes. J. LessCommon Met. 1989, 149, 207-211. 